\title{
BMJ Open Global access to COVID-19 vaccines: a scoping review of factors that may influence equitable access for low and middle-income countries
}

\author{
Elizabeth F Peacocke (D) , ${ }^{1}$ Lieke Fleur Heupink, ${ }^{1}$ Katrine Frønsdal, ${ }^{1}$ \\ Elin Hoffmann Dahl, ${ }^{2}$ Lumbwe Chola (D) ${ }^{1}$
}

To cite: Peacocke EF, Heupink LF, Frønsdal K, et al. Global access to COVID-19 vaccines: a scoping review of factors that may influence equitable access for low and middleincome countries. BMJ Open 2021;11:e049505. doi:10.1136/ bmjopen-2021-049505

- Prepublication history and additional supplemental material for this paper are available online. To view these files, please visit the journal online (http://dx.doi.org/10.1136/ bmjopen-2021-049505).

Received 26 January 2021 Accepted 03 September 2021

Check for updates

(C) Author(s) (or their employer(s)) 2021. Re-use permitted under CC BY-NC. No commercial re-use. See rights and permissions. Published by BMJ.

${ }^{1}$ Global Health, Division for Health Services, Norwegian Institute of Public Health, Oslo, Norway

${ }^{2}$ Department of Medicine, Haukeland University Hospital, Bergen, Norway

Correspondence to

Elizabeth F Peacocke;

elizabeth.peacocke@fhi.no

\section{ABSTRACT}

Objective To identify the factors contributing to equitable access to COVID-19 vaccines for low and middle-income countries (LMIC).

Methods We conducted a scoping review following the guidelines for Preferred Reporting Items for Systematic Reviews and Meta-Analyses extension for Scoping Reviews and a five-stage framework for scoping studies. We performed systematic searches for published peerreviewed literature in five databases: Medline, Embase, Web of Science, Global Index Medicus and COVID-19 Evidence Epistemonikos (August 2020, updated May 2021).

Results Systematic selection according to predefined criteria resulted in the final inclusion of 45 peer-reviewed articles, with no limitations on study design or publication type. We derived four key factors that potentially influence equitable access to COVID-19 vaccines in LMICs: (1) collectively agreed global mechanisms or frameworks; (2) bilateral purchasing, contracting, and vaccine prices; (3) vaccine manufacturing that is supported by sharing know-how; and (4) countries' strength in implementing vaccination programmes.

Conclusions This scoping review highlights the ongoing challenges for the international community in ensuring equitable access to COVID-19 vaccines for LMICs. The literature suggests that vaccine manufacturing can influence the supply of vaccines, as can the role of patent holders who can influence global governance through their role in the distribution of COVID-19 vaccines. Our findings indicate that including the principles of equitable access throughout vaccine research and development, procurement, scale-up and distribution processes can support equitable access for LMICs. Advances made with mRNA vaccines may have additional benefits in relation to expanding the manufacturing of other vaccine. Finally, the exploration and scale-up of such capacities of LMICs are likely to prove to be a valuable investment, even after the pandemic.

\section{BACKGROUND}

The Coronavirus disease (COVID-19) is a global crisis, and collective efforts are essential to curb its most devastating effects. The unprecedented demand for a vaccine has
Strengths and limitations of this study

To our knowledge, this is the first systematic scoping review of factors influencing equitable access to COVID-19 vaccines.

- Included literature was selected exclusively based on relevance to the topic (according to predefined criteria), provided that it was published in peer-reviewed journals with no further quality assessment.

- In light of the numerous daily published articles related to the COVID-19 pandemic, there might be additional relevant articles that should have been included. Hence, the list of identified factors might not be exhaustive nor completely cover the full complexity of how various factors interact.

mobilised rapid vaccine development and large-scale investment in manufacturing capacity. The outlay of capital from investors for the scale-up and production of early candidate vaccines has contributed to rapid advances in vaccine science. ${ }^{1}$ Despite these investments, the demand for safe, affordable and effective COVID-19 vaccines is expected to outstrip supply for a considerable period of time. ${ }^{2}$ To realise the maximum benefit, vaccines should be shared fairly between all nations of the world, otherwise there will continue to be differential morbidity and mortality with increased risk of virus mutations leading to even more death and disease from COVID-19, not to mention the indirect consequences to global development and economy. $^{3}$

In relation to the management of communicable disease outbreaks, the principle of shared benefits is a long-standing commitment of the WHO. ${ }^{4}$ The Global Influenza Surveillance and Response System (GISRS) suggests benefit sharing as a potential solution to incentivise global collaborative infectious disease responses and measures, and 
in return members have real-time access to pandemic response products, like vaccines. ${ }^{5}{ }^{6}$ Low and middleincome countries (LMIC) face unique challenges in accessing vaccines as they do not have the same resources to purchase vaccines and are less likely to have the know-how and technological capacity to be able to manufacture their own vaccines. They may also face uncertainty in their ability to obtain vaccines due to reduced purchasing power compared with high-income countries (HIC) when negotiating with vaccine manufacturers. ${ }^{7}$ Therefore, they are more reliant on multilaterally agreed frameworks or bilateral support to access new technologies. ${ }^{6}$ The global community has previously in part managed this with non-binding mechanisms designed to promote equitable access. The 2006 WHO Global Pandemic Influenza Action Plan (GAP), for instance, was designed to support increased vaccine supply and global vaccine manufacturing capacity by promoting technology transfer to middle-income countries (MICs). ${ }^{8}$ As established vaccine manufacturing nations, some MICs' expertise can support the scale-up of vaccine production.

Ineffective institutional mechanisms for pandemic vaccine distribution were exposed during the influenza A (H1N1) ('Swine flu') pandemic in $2009,{ }^{6}$ despite embedded principles of reciprocity and equity for the prevention and control of influenza pandemics affirmed by member states at 2003 World Health Assembly. Swine flu and the COVID-19 pandemic are reminders that there is no institutional mechanism to effectively distribute global goods such as COVID-19 vaccines. ${ }^{4}$ The Pandemic Influenza Preparedness Framework was developed following the H5N1 outbreak in Indonesia in 2005, triggering increased interest in the GISRS, which in turn led to the WHO intergovernmental process and further scrutiny of its influence on the development of influenza vaccines, and recognition of failures to ensure fairness, transparency and equity in access to vaccines for LMICs. $^{6} 910$

Specifically, for COVID-19, the WHO led the Access to COVID-19 Tools Accelerator (ACT-A) global collaboration designed to fast-track development, production and equitable access to COVID-19 tests, treatments and vaccines. ${ }^{11}$ COVAX, the vaccines pillar of the ACT-A, is an initiative whose role is proving to be integral in the equitable distribution and access to COVID-19 vaccines, by providing an alternative for LMICs that have been failed by historical bilateral vaccine donation systems. ${ }^{12}$ COVAX is co-led by the Coalition for Epidemic Preparedness Innovations (CEPI), a vaccine funding initiative, Gavi, the vaccine alliance, and WHO. Member countries of COVAX include those that have self-financing investments, but also others that are being supported through aid. COVAX aims to coordinate the vaccination of highrisk and vulnerable populations, including frontline healthcare workers across the world, through distributing 2 billion vaccine doses by the end of 2021. These vaccines will be shared between the member countries, of which 78 are HICs, and 92 are LMICs. ${ }^{13}$ Figure 1 lists the events and a timeline of initiatives introduced before and following relevant pandemics, as identified in our scoping review.

The idea that access and distribution of COVID-19 vaccines should be equitable across countries is widely supported, but what equity means in this context is often not specified. From the perspective of LMICs, equitable access to a vaccine is fundamentally linked to a fair and transparent global distribution framework. ${ }^{14}$ Hence, for the purpose of this review, equitable access is interpreted as all countries, and their populations, having equal access to COVID-19 vaccines irrespective of the income status of the country. Further, we considered a COVID-19 vaccine as an essential medicine (Essential medicines are those that satisfy the priority healthcare needs of the population). We have used the WHO definition of health equity (Health equity or 'equity in health' implies that ideally everyone should have a fair opportunity to attain their full health potential and that no one should be disadvantaged from achieving this potential). ${ }^{15} 16$ In its first phase, COVAX plans to allocate vaccines in proportion to countries' total population so that all countries receive doses to cover $20 \%$ of their population. ${ }^{17}{ }^{18}$ Alternative proposals exist, including the Fair Priority Model proposed by a group of ethicists. This model goes beyond proportional allocation by proceeding with allocation of vaccines in three phases, which would in the first instance prioritise the prevention of more urgent harms. ${ }^{19} 20$ The ethical rationale behind this model argues that proportional allocation, as suggested by WHO and COVAX, is not the fairest solution, as it implies that some countries with relatively lower risk of death and disease from COVID-19 would receive access to vaccines at the expense of other countries that are facing more exposure. ${ }^{20}$

The objective of this scoping review was to identify and summarise those factors that contribute to the equitable access of COVID-19 vaccines for LMICs. To our knowledge, the literature related to the equitable access of COVID-19 vaccines relevant for LMICs has not yet been systematically investigated. The review is considered highly relevant as it can provide lessons from previous experiences and perspectives on equitable access to pandemic vaccine by identifying key factors that could guide implementation of future initiatives to ensure equitable access.

\section{METHODS}

We performed systematic scoping searches following the Preferred Reporting Items for Systematic Reviews and Meta-Analyses extension for Scoping Reviews as indicated in figure 2, and were guided by the Arksey and O'Malley's five-stage framework for scoping studies through the steps of the review. ${ }^{21}{ }^{22}$ The study protocol was peer reviewed by methodological and subject experts at the Norwegian Institute of Public Health (online supplemental appendix 1).

Based on predefined inclusion criteria (table 1), we systematically searched in the following five databases: Medline (PubMed and Ovid), Embase, Web of Science, 


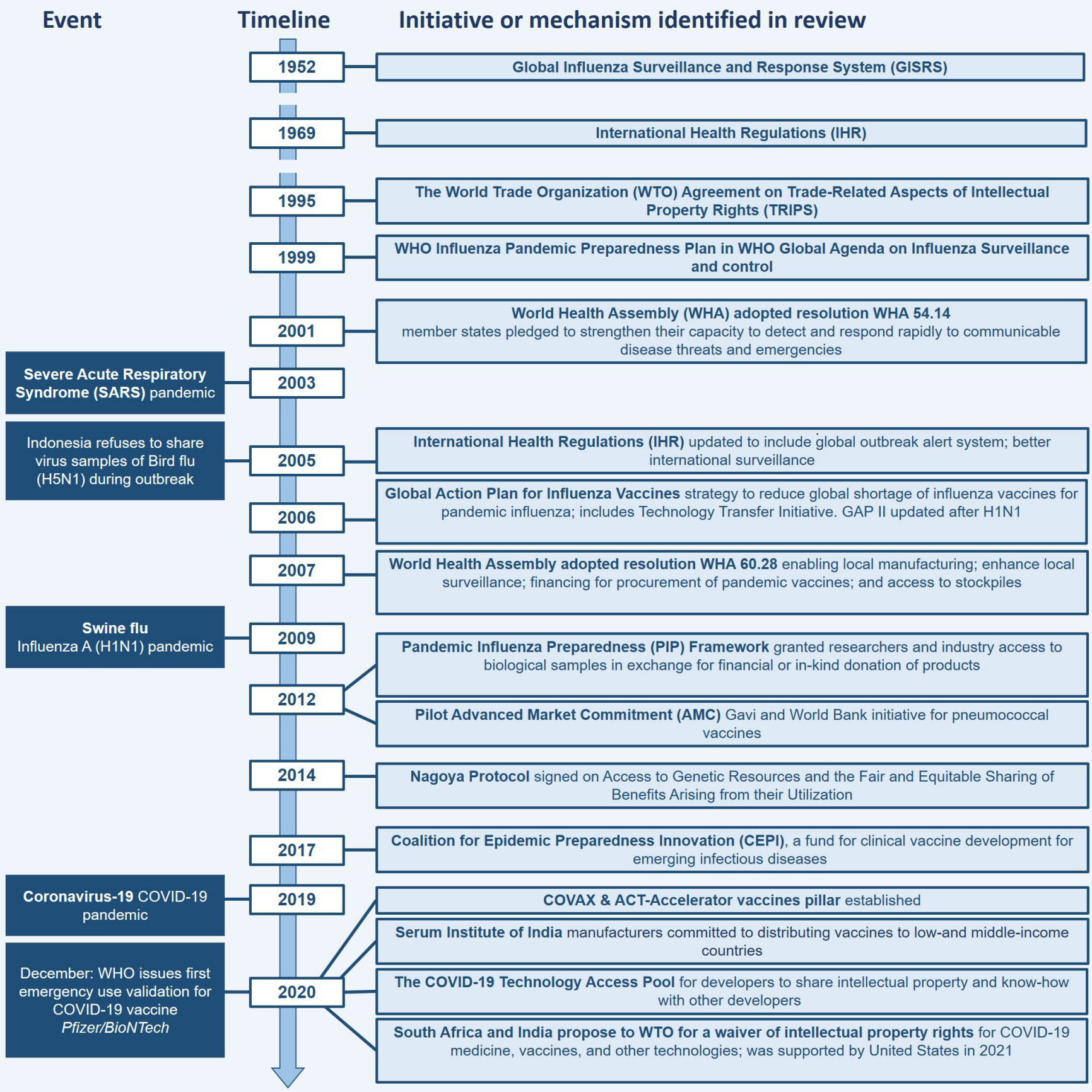

Figure 1 Timeline of events and relevant initiatives. ACT, Access to COVID-19 Tools; GAP, Global Pandemic Influenza Action Plan.

Global Index Medicus (WHO) and COVID-19 Evidence Epistemonikos. The search strategy was based on the following keywords and terms and combinations of these (ie, coronavirus, COVID-19, SARS-CoV, equity, LMIC, pandemic and (influenza) vaccine) (online supplemental appendix 2). An information specialist, in collaboration with coauthors, developed the search strategies for the different databases. The search was performed on 28 August 2020 and updated on 12 May 2021. Only published literature in peer-reviewed journals was eligible for inclusion, with no limitations on study design nor publication type. The articles for extraction were exclusively chosen based on relevance to the topic of identifying and describing potential factors related to equitable access to pandemic or COVID-19 vaccines, with no further quality assessments.

Publications were screened based on title and abstract according to the inclusion criteria (table 1). Two reviewers independently selected articles to be considered for full text screening. Selected articles were then read in full and considered for inclusion or exclusion by two different reviewers. Final decisions on inclusion of relevant articles were determined through consultation between three of the reviewers. Disagreements were resolved through 


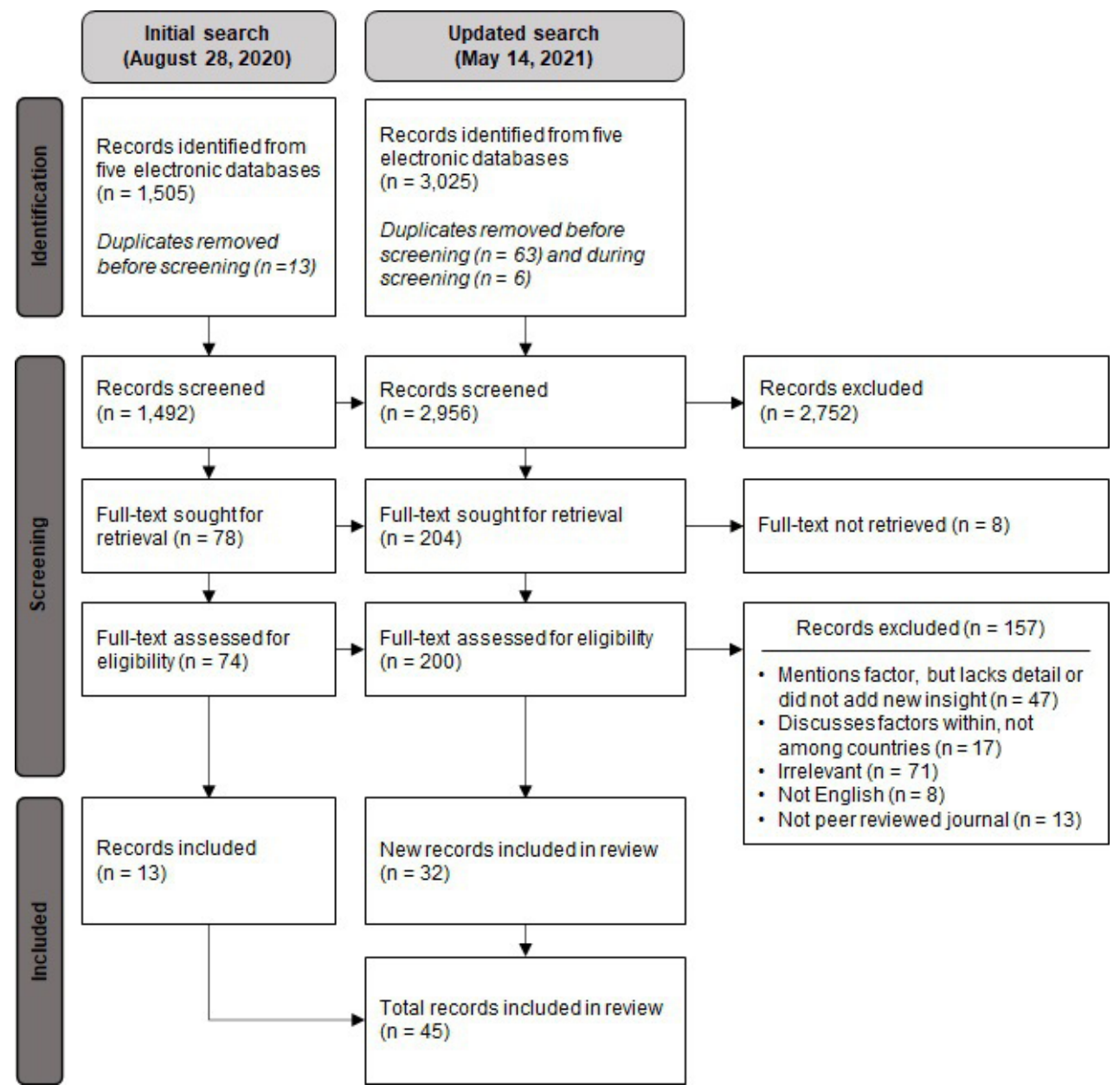

Figure 2 Preferred Reporting Items for Systematic Reviews and Meta-Analyses (PRISMA) flow chart for selection of articles.

discussions to reach consensus. See online supplemental appendix 3 for the list of the excluded articles and reasons for exclusion.

Data extraction was performed by one reviewer and verified by a second. We used a data extraction form designed specifically for this scoping review. We extracted information on the setting; discussion on equity, access, allocation or prioritisation of pandemic vaccines; other equity aspects; challenges in implementing equitable access to vaccination between countries; and recommendations for strengthening equitable access to vaccination

\begin{tabular}{ll}
\hline Table $1 \quad$ Inclusion criteria \\
\hline Criterion & Inclusion \\
\hline Time & $\begin{array}{l}\text { 1 January 2002 to 12 May 2021 } \\
\text { English }\end{array}$ \\
\hline Type of article & $\begin{array}{l}\text { Published in peer-reviewed } \\
\text { journals }\end{array}$ \\
\hline Article focus & $\begin{array}{l}\text { Pandemic vaccines including } \\
\text { influenza or COVID-19 vaccine }\end{array}$ \\
Outcomes & $\begin{array}{l}\text { Factors influencing equitable } \\
\text { access to a pandemic vaccine } \\
\text { including COVID-19 vaccines }\end{array}$ \\
\hline
\end{tabular}

(online supplemental appendix 4). The analytical process followed the principles of thematic synthesis. The article by Liu et al was identified as an index paper as it suggested a framework that closely reflected the focus of our scoping review. ${ }^{23}$ The themes identified in this article were used as basis to extract and categorise our findings, and were further refined during analysis, where we identified potential factors influencing equitable access to COVID-19 vaccines in LMICs.

\section{RESULTS}

Excluding duplicates, our search identified 3025 unique citations (figure 2). Screenings first based on title and abstract, then on full text resulted in the final inclusion of 45 articles (described in online supplemental appendix $5)$.

We categorised the identified themes from the included citations into four factors influencing access to COVID-19 vaccines in LMICs: (1) collectively agreed global mechanisms or frameworks can contribute to equitable access to COVID-19 vaccines; (2) bilateral purchasing, contracting and vaccine prices can influence fair access; (3) largescale vaccine manufacturing that is supported by sharing know-how can facilitate increased supply and access to 
Table 2 Summary of identified factors contributing to equitable access to COVID-19 vaccines

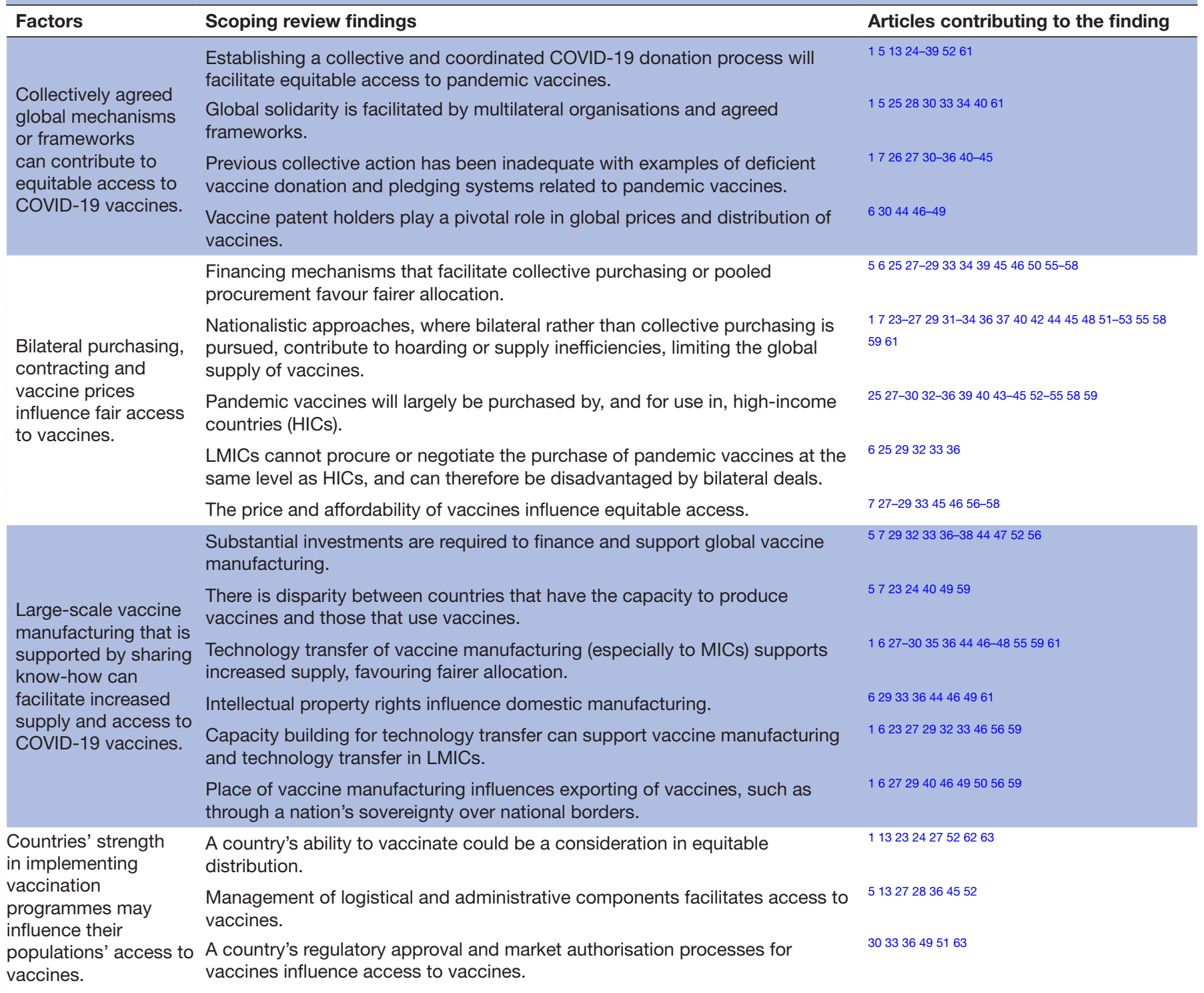

LMICs, low and middle-income countries; MICs, middle-income countries.

COVID-19 vaccines; and (4) countries' strength in implementing vaccination programmes may influence their populations' access to vaccines (table 2).

- Collectively agreed global mechanisms or frameworks can contribute to equitable access to COVID-19 vaccines.

Most articles indicated collective action as being key to contribute to equitable access. ${ }^{15} 613$ 24-50 Global collective agreements should be driven by multilateral agencies that have the global mandate to convene interest groups, advocate for collective response measures, as well as the investment, procurement and distribution of pandemic vaccines. ${ }^{51}$ These measures may be addressed by prompt agreement on equitable access. ${ }^{5} 303852$

The reviewed literature suggests that historic vaccine donation and pandemic influenza pledging systems have been insufficient mainly due to the lack of legal obligation to act or the lack of penalty for parties who breach conditions. ${ }^{1262730-3640-4345}$ To mitigate this, it is proposed that collective approaches need to be binding. ${ }^{35}$ Actually, such a legal framework that has been ratified by 171 countries already exists, the International Covenant on Economic, Social and Cultural Rights (1966); however, it has not achieved its intended purpose for countries to take steps to ensure the right to health and the benefits of scientific research, without discrimination. ${ }^{34} 42$ In spite of these so-called failures of collective action, there is wide acceptance of the moral argument that HICs should support LMICs in equitable access to pandemic vaccines, recognising that any collective purchasing will have inherent inequalities related to existing power dynamics between the Global North and the Global South, and recognising that the status quo historically favoured HICs over LMICs. ${ }^{25}{ }^{35}$ Specifically, for vaccine allocation, there are historical examples of manufacturers not reliably committing to reserving production of pandemic vaccines to LMICs. ${ }^{6} 2640$ 
Bilateral solutions threaten collective action by enabling some countries to queue jump. ${ }^{129}$ These approaches will always be pursued during global crises, as has been demonstrated during COVID-19, and as such cannot be avoided. ${ }^{32}$ McAdams et al therefore suggest that it comes down to how these bilateral arrangements are structured using two deals from different US government agencies, the Biomedical Advanced Research and Development Authority (BARDA) who has a deal with AstraZeneca, and the US Department of Health and Human Services who secured 100 million doses of Pfizer, as examples. ${ }^{32}$ The authors suggest that the deal negotiated by BARDA benefits USA, AstraZeneca and the rest of the world by supporting the gaining, and sharing, of knowledge through its funding of advanced clinical studies, vaccine manufacturing technology transfer, process development and scaled-up manufacturing, which in turn supports more vaccines and increased availability. In contrast, the Pfizer deal only supports US and Pfizer interests. The article concludes that BARDA's deal will result in more vaccines for LMICs, regardless of whether HICs vaccinate their own populations first. ${ }^{32}$

COVAX is the supported mechanism and widely promoted in the literature included in this review, yet the facility has faced criticisms related to transparency, limited knowledge sharing and initally struggled with lacking political and financial commitment. ${ }^{31}{ }^{53}$ It has also faced challenges related to managing the role of patent holders who have played a determining role in distribution of their medical countermeasures. This affects global governance, with patent holders maintaining influence over the distribution of patented technologies during a pandemic, a power that rests with few pharmaceutical companies controlling the global supply and distribution of vaccines. ${ }^{46} 48$

The global prices of respective vaccines are not uniform across settings, with the price of a COVID-19 vaccine influenced by its patent, indicating the influence patent holders have in the distribution of vaccines. ${ }^{29} 4548$ To counteract the inequality in global distribution, in October 2020, a proposal was made by India and South Africa to the World Trade Organization (WTO) requesting a temporary waiver of certain provisions of the TradeRelated Aspects of Intellectual Property Rights (TRIPS) Agreement, based on the need to prevent, contain and treat COVID-19. ${ }^{44} 48$ There is no consensus in the literature included in this review on the benefits of the waiving of intellectual property rights (IPR). Those against the waiver arguing that it is not patent protection that is the barrier to introducing generic vaccines, ${ }^{42} 44$ but rather the lack of knowledge in the public domain and shortages of vaccine supplies. ${ }^{1}$ The implications on national manufacturing, including a country's ability to enact compulsory licensure under TRIPS, are discussed later in this article.

- Bilateral purchasing, contracting and price can influence fair access to vaccines.

Through their greater advanced purchasing power and their ability to manufacture vaccines, HICs have a track record of dominating the global supply of pandemic vaccines. In 2021, $51 \%$ of the initial supply of COVID-19 vaccines had been purchased for $13 \%$ of the world's population, mostly residing in HICs, ${ }^{28} 3040$ indicating that fair vaccine allocation is hindered by the inability of LMICs to procure or negotiate access to pandemic vaccines at the same level as HICs. ${ }^{654}$

Vaccine development under the COVID-19 pandemic has highlighted the conflicting roles between private capital and access to essential healthcare technologies. Final stage research and development (R\&D) of vaccines (and other medical technologies) is largely led by multinational pharmaceutical companies who are incentivised by IPR and return on investment, thus perpetuating structural market-based inequalities of supply and demand. This affects the total quantity of vaccines produced, which, in the case of influenza vaccines, has affected LMICs as it has been perceived that there is 'lower demand' in these markets. ${ }^{35} 50$ During this recent pandemic, substantial public funding, which has historically been targeted more towards early- stage development, has also been invested in the late-stage development of multiple COVID-19 vaccines contributing to global market distortions. ${ }^{32} 363755$

Pooled procurement is mentioned in the literature of this review as a means to support equity, with Advance Purchase Agreements (APA) and Advance Market Commitments (AMC) being the most common mechanisms identified in our review to facilitate access for LMICs. ${ }^{5} 625282933343945465055-57$ APAs are contracts with a specific product developer, whereas an AMC is a global market commitment. ${ }^{39}$ The AMC was first introduced in 1999 for the development of a late-stage pneumococcal vaccine, with the intention to shorten the time to introduction of a vaccine to LMICs. ${ }^{39}$ Under COVID-19, APAs have been widely used to secure priority access to a scarce resource (when one party has committed to buy a specific number or percentage of doses prior to development), the influential factor for equitable access being whether they promote the interests of one country or several, and if they include LMICs. ${ }^{5630344150}$

Bilateral deals contribute to supply inefficiencies and threaten collective approaches to the procurement of vaccines, for example, national APAs initiated by countries that are also members of COVAX (not exclusively, but mainly HICs). ${ }^{32} 363753555758$ At the beginning of the COVID-19 pandemic, HICs went ahead to purchase large quantities of COVID-19 vaccines. ${ }^{31}$ The necessity for transparency of contractual clauses, especially relating to pricing, licensing and purchase commitments, was identified in the review as potentially negative since global coordination efforts will suffer unless vaccine manufacturers can be trusted to responsibly decide which countries' vaccine orders should be prioritised. ${ }^{3436}$

Bilateralism is not limited to relationships between countries and vaccine manufacturers. During the COVID-19 pandemic, bilateral deals have also been struck between countries to directly distribute vaccines. For example, both the Russian and Chinese government-owned and 
operated vaccine manufacturers have bilateral arrangements with other countries, such as India, Vietnam, Mexico, Brazil and Ethiopia, to guarantee the supply of vaccines. ${ }^{28} 295559$

- Large-scale vaccine manufacturing that is supported by sharing know-how can facilitate increased supply and access to COVID-19 vaccines.

Several articles included in this review suggest that substantial additional financial and capacity investment is required to further global vaccine manufacturing. ${ }^{5} 729323336384447525660$ Vaccine development is multifaceted, and manufacturing during a pandemic faces unprecedented challenges in scale and complexity. ${ }^{51}$ A limited number of HICs, and some MICs, have vaccine manufacturing capacity, resulting in a disparity between countries that have the capacity to produce vaccines and those that need access to those vaccines. ${ }^{5724404959}$ Nhamo et al reported that development activity for COVID-19 vaccines is almost non-existent in LMICs. ${ }^{33}$ The majority of development activity is in Asia, with 12 (52\%) COVID-19 vaccine development programmes, followed by Europe $(17 \%)$ and North America with four programmes each $(17 \%) .{ }^{33}$ A few MICs (Brazil, India and Peru) have capitalised on their clinical testing or manufacturing capacity efforts by leveraging these for purchase agreements with vaccine manufacturers. ${ }^{29}$ Limited capacity affects the global availability of pandemic vaccines for two reasons. First, the world is unable to manufacture the quantity of vaccines demanded, and second, a manufacturing country has the sovereign authority over goods produced within its borders with most countries in the world having legislation in place that require companies to manufacture and prioritise domestic consumption. ${ }^{33} 4950$ In situations where it is enforced, government intervention may hinder global access through limitations to distribution.

For technology transfers to work, there needs to be a patent holder that is willing to share the intellectual property and a manufacturing facility that can receive it. The findings from this review suggest that MICs with vaccine manufacturing capability can play an important role to support and fill the forecasted gap in international vaccine manufacturing capacity, but this requires technology transfer and capacity building to manufacture vaccines that meet the same efficacy and quality standards as the original vaccine. ${ }^{1627-3035364446-49} 555961$ Vaccine manufacturing know-how can include vaccine developers by sharing the intellectual property of vaccine manufacturing processes or relaxing patent rights. ${ }^{6} 293336444661$ One article included in this scoping review suggests that for viral vector vaccines (eg, AstraZeneca and Johnson \& Johnson), MICs with less advanced manufacturing capacity can contribute with the fill-and-finish stage of the process, rather than producing the active solution of the vaccine. $^{47}$

Under the WTO TRIPS Agreement, countries have a right for the compulsory licensure of products in certain circumstances. In practice, this means that a country can produce a patented product or process without the consent of the patent owner, as demonstrated by Canada, Chile and Ecuador in their pandemic response. ${ }^{29}$ The discussion related to the TRIPS waiver is especially important to LMICs, who recall recent historical experiences from South Africa where patents obstructed access to life-saving medicines for the treatment of HIV/AIDS. ${ }^{42}$ Advocates for the COVID-19 products TRIPS waiver argue that significant public monies have contributed to the development of these patents thus waiving IPR will support vaccine development and manufacturing, and that some countries are already undermining existing TRIPS flexibilities through restrictive free trade agreements. ${ }^{4255561}$ Proponents against governments' enacting patent waivers claim that they contribute to inefficiencies by diverting raw materials and supplies away from effective manufacturers. ${ }^{47}$ Compulsory licences are not considered by these proponents as being a practical tool to rapidly expand access to vaccines, instead they support voluntary licensure, for instance, AstraZeneca's arrangements with Indian and Brazilian manufacturers. ${ }^{1} 4447$ A related issue impacting on manufacturing capacity is the use of limited manufacturing capacity on all vaccine candidates. So and Woo (2019) caution that a weakness of prematurely exhausting capacity for vaccines that show early safety and efficacy promise is that manufacturing capacity will then be locked into first generation vaccines, and may be a bottleneck for manufacturing capacity for second generation more effective vaccines. ${ }^{55}$

Finally, two noteworthy initiatives are identified in the literature reviewed: (1) to increase vaccine supply, GAP (2006-2016), is a strategy to reduce global shortages of influenza and pandemic vaccines that supports technology transfer ${ }^{30} 42$; and (2) the recent COVID-19 Technology Access Pool (C-TAP) (2020) proposed by Costa Rica and adopted by WHO (endorsed by 35 mainly MICs and five HICs). C-TAP calls for the voluntary sharing of knowledge, intellectual property and data, as well as a guarantee of free access and use by WHO member countries for drugs and vaccines that are developed. ${ }^{29} 3536$ Given the world's limited manufacturing capacity, the use of technology transfer and pooling of vaccines could help alleviate a massive shortage of vaccines given the scale of the need. ${ }^{38}$

- Countries'strength in implementing vaccination programmes may influence their populations' access to vaccines.

The findings from this scoping review further suggest that the ability of a country to implement a mass vaccination programme is an important factor that may influence equitable access. ${ }^{23}$ Vaccination programmes are resource intensive; therefore, to maximise the benefit of COVID-19 vaccines and reduce waste due to improper implementation, it has been suggested that allocation frameworks should consider a country's ability to vaccinate. ${ }^{1} 13232427526263$ Most LMICs have well-structured immunisation programmes for polio, measles, smallpox, etc, facilitated by organisations such as UNICEF and Gavi, which could support a large-scale pandemic vaccination programme. It has been reported that Gavi, for example, 
has sought to expand its Cold Chain Equipment Optimization Program. ${ }^{27}$ More than half of the countries in the world lack robust programmes to tackle seasonal influenza, despite most associated death and severe disease from influenza occurring in countries of the Global South. ${ }^{63}$ The down prioritisation of seasonal influenza vaccination for older populations in LMICs compared with HICs is a vulnerability for the roll-out of COVID-19 vaccines. ${ }^{30336263}$ Ruscio and Hotez noted that an attempt to fill this gap has been made by the recently published WHO Global Influenza Strategy 2019-2030. ${ }^{63}$

Vaccine roll-out requires stable cold chain and supply processes for the necessary logistical and administrative components to facilitate distribution of vaccines, including financing the in-country delivery of vaccines, from cold chain to administration. ${ }^{13} 2728364560$ Different vaccines have different temperatures for deployment, which influences supply of vaccine to communities. ${ }^{1327454760}$ This is a particular challenge in sub-Saharan Africa, where only $28 \%$ of healthcare facilities have a reliable energy supply. ${ }^{13}$ In this context, vaccines that require only one dose or those that can be stored at room temperature are more likely to facilitate equitable access. ${ }^{45}$ There is also an opportunity to explore the use of new containers and packaging that support distribution. For example, preformed plastic vials are being successfully used for oral rotavirus and cholera vaccines. ${ }^{62}$ Data solutions should also be considered, as these could support alternative vaccine delivery systems for target groups, as well as being an important tool to capture the populations' vaccination history. $^{28}$

Smooth regulatory and market authorisation processes for vaccines can facilitate the distribution of vaccines. ${ }^{30} 33364963$ One article from this scoping review highlighted the importance of clinical vaccine studies in LMICs and HICs alike, to support the fast-tracking of market authorisation, as local clinical trial data are a recognised grounds for delay to introduce some vaccines into countries' immunisation programmes. ${ }^{33}$ Delays for products preventing or treating infectious diseases are cited at being between 4 and 7 years from first approval in an HIC and final approval in a country in sub-Saharan Africa. ${ }^{36}$

\section{DISCUSSION}

This study identified four key factors that carry the potential to promote fairer global access to COVID-19 vaccines. Our findings suggest that an international approach is necessary to minimise the spread of a pandemic. A priori of this review, there has been broad international support for the principles of equitable distribution of medical countermeasures, as demonstrated by universal support for WHO resolutions. ${ }^{4} 891464-67$ COVID-19 is no exception, with relevant commitments passed in months following the declaration of the pandemic. ${ }^{1768-71}$ This has, however, not translated into binding global commitments. The establishment of ACT-A and COVAX was partly a recognition of historic failures, as highlighted in the findings of this review. Co-led by CEPI and Gavi (in partnership with WHO), both were established with a commitment of equitable access to medicines in their ethos. As multicountry-endorsed initiatives, they can be considered good candidates to lead the process for equitable distribution of COVID-19 vaccines. ${ }^{1272-74}$

The risks that sovereign states pose to equitable access by acting in their national interest, including bilateral agreements with pharmaceutical companies, buying up vaccine stocks during clinical development phases and vaccine hoarding, were anticipated in our findings and have largely been realised. ${ }^{31}$

COVAX's pooled procurement through APAs has faced challenges, initially in accessing the necessary financing, which in turn delayed securing supply against other HIC purchasers. ${ }^{1} 142729$ In addition, it has also faced critique on how price has been determined and whether any costs can be recovered if vaccine candidates fail. ${ }^{34} 3975$ While COVAX has attempted to meet foreseen gaps, ${ }^{14}$ it has been challenged by national interests, highlighted recently with announcements that Australia is purchasing booster shots, ${ }^{76}$ and that several HICs plan to donate parts of their surplus vaccines to LMICs directly, ${ }^{77}$ rather than through the COVAX facility, making vaccines a tool of geopolitics.

The pandemic has shown several examples of countries enacting their sovereign authority over goods produced within its borders, one example being the USA's invocation of the Defense Production Act reducing export of active pharmaceutical ingredients, ${ }^{78}$ which slowed the production of the AstraZeneca vaccine by its collaborator Serum Institute in India. ${ }^{79}$ More recently, in response to a devastating second wave of COVID-19 infections, the Indian government imposed an export ban on vaccines, redirecting these to the domestic market, leading to a further slowdown in doses available to the COVAX facility. ${ }^{80}$ Additionally, the use of vaccine manufacturing capacity to scale up production of COVID-19 vaccines will likely impact on the production of other vaccines such as influenza, measles, mumps and rubella with a disproportionate impact on the global poor. ${ }^{81}$

The roll-out of population-wide immunisation programmes has put most governments to the test, with many being critiqued for botched roll-outs. Australia and Japan are two HICs that have faced criticism over the delays related to the logistical issues of setting up such a large vaccination programme. ${ }^{82} 83$ In June 2020 , it was reported that less than $15 \%$ of imported vaccine doses in Japan had been used. ${ }^{83}$ In addition, Japan is one example of a country whose vaccine implementation was interrupted by national regulatory requirements for domestic clinical trials, which could not be undertaken due to low numbers of COVID-19 cases. This prevented Japan from registering international clinical trials to meet national requirements related to safety and efficacy. ${ }^{83}$ LMICs face similar regulatory delays, ${ }^{27} 33$ seemingly a bureaucratic hurdle that could be planned for, especially given 
the emergency nature of the pandemic, and that these vaccines have already met stringent regulatory standards (ie, the US Food and Drug Administration or fro the European Medicines Agency).

For LMICs, the well-established child immunisation programmes have targeted parts of the population; however, few LMICs have extensive experience with vaccination of the general adult population. This makes the COVID-19 the 'first' large-scale adult vaccination programme aiming to achieve high coverage rates. ${ }^{84} 85$ To facilitate implementation, COVAX has integrated a 'Country Readiness and Delivery (CRD) work stream' to support the introduction of COVID-19 vaccines into national vaccination programmes. ${ }^{86}$ However, lack of infrastructure, short shelf-life and vaccine hesitancy challenge the vaccine uptake and distribution of vaccines, which has led to vaccine wastage (eg, South Sudan and Malawi) or redeployment to avoid this outcome (eg, the Democratic Republic of Congo to Ghana and Madagascar) ${ }^{87}$ Other countries, such as Bhutan, have impressed with their swift implementation strategies vaccinating $90 \%$ of their eligible adult population in 2 weeks. ${ }^{88}$

The potential long-term solution to equitable access highlighted in our scoping review is the need to broaden the basis of manufacturing of vaccines. A success of the COVID-19 response has been the high effectiveness of novel mRNA vaccines that (pre-COVID-19) were yet to enter human clinical trials. However, few manufacturers have the necessary know-how to set up mRNA manufacturing capacity, resulting in centralised production in a few locations in the Global North. The WHO has relaunched C-TAP to support a 'global one-stop shop for developers' following nothing being shared by any pharmaceutical company within the first 12 months of the launch of the C-TAP open platform in mid-2020. ${ }^{80}$ The TRIPS patent waiver of COVID-19 products received historical support from the incoming US government administration in May 2021, and has since moved into text-based discussions. ${ }^{91}$

It is widely acknowledged in the literature that ramping up production in LMICs while meeting the necessary quality standards takes time and will require extensive knowledge transfer from pharmaceutical companies. Globally, 15 MICs have vaccine production capacity to support the global supply of vaccines, but only 12 have WHO prequalification status which is instrumental for quality-assured generic vaccine candidates. ${ }^{27}$ The pandemic has further uncovered the need for more vaccine manufacturing capacity across the whole world. The acknowledgement of the incommensurable role of manufacturing capacity is captured in a project led by CEPI to map out manufacturing capacity for use in future pandemics. ${ }^{92}$ Further, to counteract this, the African Union and African Centers for Disease Control and Prevention launched a partnership to increase future vaccine production in Africa. ${ }^{93}$

A limitation of this scoping review is that literature was exclusively chosen based on relevance to the topic of identifying and describing potential factors influencing equitable access to COVID-19 vaccines, meaning that we have included commentaries, editorials, essays and viewpoints. We determined that these perspectives were of importance to our research aim, regardless of the type of publication, as the aim was to identify factors and not to assess or evaluate them or compare their relative importance. In light of the nature of the current situation and the topic, restricting the review to only include publications of original research with journal publication time frames did not seem appropriate. To manage this, articles were only included if they were published in a peer-reviewed journal.

\section{CONCLUSION}

According to current available published literature, equitable access to vaccines proves to be an ongoing challenge. The uneven global distribution of vaccines is starkly shown in the current divide of vaccine coverage where the wealthiest nations have received more than $87 \%$ of the vaccines while LMICs just $0.2 \% .^{94}$ Altogether, findings identified in this scoping review converge towards vaccine manufacturing being of high importance in the supply of vaccines. Future research could explore the contribution of MICs to facilitate vaccine supply in a pandemic, including some of the challenges of maintaining these facilities outside of a pandemic. Building on COVID-19 success, mRNA technologies will be used for other vaccines in the future, thus the exploration and scale-up of such capacities on the African continent is likely to prove to be a valuable investment, even after the pandemic. Moreover, despite the length of time it takes to build and certify vaccine manufacturing facilities, steps can be taken to share the know-how of the manufacturing of effective vaccines, although the full possibilities of relaxing of patent and IPR are yet to be realised and can contribute to equitable access.

Another issue identified in the literature was the role that patent holders play in global governance through influencing the distribution of COVID-19 vaccines, this needs more transparency. The importance of including equitable access principles to all levels of development also seemed to be relevant, for example, throughout vaccine $\mathrm{R} \& \mathrm{D}$, procurement, scale-up and distribution.

\section{Twitter Elizabeth F Peacocke @bliiss}

Acknowledgements Thank you to the following people who helped develop or offered their feedback on the original concept of this scoping review: Marit Johansen (information specialist), Benedikte Louise Alveberg, Tenu Avafia, Julia Bidonde, Anita Haslie, Unni Gopinathan, Adam Kamradt-Scott, Ida Kristine Lindkvist, Jasper Littman, Trygve Ottersen, Judit Rius Sanjuan, Ingvil Sæterdal, Christine Årdal.

Contributors EP and LC: concept development, drafting the protocol, data extraction, analysis, writing and review. LFH: data extraction, support with analysis, writing and review. KF: methodology, review of extraction, writing and review. EHD: writing and review.

Funding This work was partially supported by the Evaluation Department of the Norwegian Agency for Development Cooperation (Norad) in their role as a member of the OECD COVID-19 Global Evaluation Coalition (grant number 1900737) and Norad Department of Education and Health (grant number QZA-18/0102).

Disclaimer The funders had no role in the study design, data collection and analysis, decision to publish or preparation of the manuscript.

Competing interests None declared. 
Patient consent for publication Not required.

Ethics approval Ethical clearance was not required as the review used secondary data that are available in the public domain.

Provenance and peer review Not commissioned; externally peer reviewed.

Data availability statement All data relevant to the study are included in the article or uploaded as supplementary information.

Supplemental material This content has been supplied by the author(s). It has not been vetted by BMJ Publishing Group Limited (BMJ) and may not have been peer-reviewed. Any opinions or recommendations discussed are solely those of the author(s) and are not endorsed by BMJ. BMJ disclaims all liability and responsibility arising from any reliance placed on the content. Where the content includes any translated material, BMJ does not warrant the accuracy and reliability of the translations (including but not limited to local regulations, clinical guidelines, terminology, drug names and drug dosages), and is not responsible for any error and/or omissions arising from translation and adaptation or otherwise.

Open access This is an open access article distributed in accordance with the Creative Commons Attribution Non Commercial (CC BY-NC 4.0) license, which permits others to distribute, remix, adapt, build upon this work non-commercially, and license their derivative works on different terms, provided the original work is properly cited, appropriate credit is given, any changes made indicated, and the use is non-commercial. See: http://creativecommons.org/licenses/by-nc/4.0/.

ORCID iDs

Elizabeth F Peacocke http://orcid.org/0000-0001-6930-9581

Lumbwe Chola http://orcid.org/0000-0001-6488-2813

\section{REFERENCES}

1 Eccleston-Turner $\mathrm{M}$, Upton $\mathrm{H}$. International collaboration to ensure equitable access to vaccines for COVID-19: the ACT-Accelerator and the COVAX facility. Milbank Q 2021;99:426-49.

2 Gavi the Vaccine Alliance. COVAX, the act-accelerator vaccines pillar- Insuring accelerated vaccine development and manufacture: Gavi; 2020 [cited 2020 August 3]. Available: https://www.gavi.org/ sites/default/files/covid/COVAX-Pillar-background.pdf [Accessed 3 Aug 2020].

3 National Academies of Sciences E, Medicine, Health. Framework for equitable allocation of COVID-19 vaccine. Washington (DC): Nationa Academies Press, 2020: 10. 2.

4 WHA56. 19 prevention and control of influenza pandemics and annual epidemics. Resolution of the Fifty-Sixth World Health Assembly Tenth plenary meeting, 2003.

5 Bollyky TJ, Gostin LO, Hamburg MA. The equitable distribution of COVID-19 therapeutics and vaccines. JAMA 2020;323:2462.

6 Eccleston-Turner M. The pandemic influenza preparedness framework: a viable procurement option for developing states? Med Law Int 2017;17:227-48.

7 Fedson DS, Dunnill P. Commentary: From scarcity to abundance: pandemic vaccines and other agents for "have not" countries. $J$ Public Health Policy 2007;28:322-40.

8 World Health Organization. Global pandemic influenza action plan to increase vaccine supply. Geneva: World Health Organization, 2006.

9 World Health Organization. Brief history of the development of the framework on sharing influenza viruses and access to vaccines and other benefits 2011. Available: https://www.who.int/influenza/pip/ history/en/ [Accessed 15 Dec 2020].

10 World Health Organization. Pandemic influenza preparedness framework for the sharing of influenza viruses and access to vaccines and other benefits. WHO, 2011.

11 World Health Organization. The access to COVID-19 tools (ACT) accelerator. WHO, 2020.

12 Gavi the Vaccine Alliance. About our alliance. Gavi the vaccine alliance. Gavi the Vaccine Alliance, 2020.

13 Herlitz A, Lederman Z, Miller J, et al. Just allocation of COVID-19 vaccines. BMJ Glob Health 2021;6:e004812.

14 Ana Santos R. The COVID-19 Vaccine Race: Intellectual Property, Collaboration(s), Nationalism and Misinformation. SSRN2020.

15 World Health Organization. Health topics: health equity 2020. Available: https://www.who.int/topics/health_equity/en/ [Accessed 12 Aug 2020].

16 World Health Organization. Essential medicines and health products. Essential medicines definition 2020. Available: https://www.who.int/ medicines/services/essmedicines_def/en/ [Accessed 13 Aug 2020].
17 World Health Organization. More than 150 countries engaged in COVID-19 vaccine global access facility 2020. Available: https:// www.who.int/news-room/detail/15-07-2020-more-than-150countries-engaged-in-covid-19-vaccine-global-access-facility [Accessed 15 Jul 2020]

18 World Health Organization. WHO concept for fair access and equitable allocation of COVID-19 health products: final working version 9 September 2020. Geneva: World Health Organization, 2020.

19 Emanuel EJ, Persad G, Kern A, et al. An ethical framework for global vaccine allocation. Science 2020;369:1309-12.

20 Herzog LM, Norheim OF, Emanuel EJ, et al. Covax must go beyond proportional allocation of covid vaccines to ensure fair and equitable access. BMJ 2021;372:m4853.

21 Tricco AC, Lillie E, Zarin W, et al. PRISMA extension for scoping reviews (PRISMA-ScR): checklist and explanation. Ann Intern Med 2018;169:467-73.

22 Arksey H, O'Malley L. Scoping studies: towards a methodological framework. Int J Soc Res Methodol 2005;8:19-32.

23 Liu Y, Salwi S, Drolet BC. Multivalue ethical framework for fair global allocation of a COVID-19 vaccine. J Med Ethics 2020;46:499-501.

24 DeFrancesco L. Whither COVID-19 vaccines? Nat Biotechnol 2020;38:1132-45.

25 Holzer F, Luna F, Manriquez T, et al. A matter of priority: equitable access to COVID-19 vaccines. Swiss Med Wkly 2021;151:w20488.

26 Fidler DP. Vaccine nationalism's politics. Science 2020;369:749.

27 Forman R, Shah S, Jeurissen P, et al. COVID-19 vaccine challenges: what have we learned so far and what remains to be done? Health Policy 2021;125:553-67.

28 Gray G, Van der Heever A, Madhi S, et al. The Scientists' Collective 10-point proposal for equitable and timeous access to COVID-19 vaccine in South Africa. S Afr Med J 2021;111:89-94.

29 Guzman J, Hafner T, Maiga LA, et al. COVID-19 vaccines pricing policy options for low-income and middle- income countries. BMJ Glob Health 2021;6:e005347.

30 Kamradt-Scott A, Lee K, The LK. The 2011 pandemic influenza preparedness framework: global health secured or a missed opportunity? Polit Stud 2011;59:831-47.

31 Kupferschmidt K, obstacles D. Despite obstacles, WHO unveils plan to distribute vaccine. Science 2020;369:1553.

32 McAdams D, McDade KK, Ogbuoji O, et al. Incentivising wealthy nations to participate in the COVID-19 vaccine global access facility (COVAX): a game theory perspective. BMJ Glob Health 2020;5:e003627.

33 Nhamo G, Chikodzi D, Kunene HP, et al. COVID-19 vaccines and treatments nationalism: challenges for low-income countries and the attainment of the SDGs. Glob Public Health 2021;16:319-39.

34 Phelan AL, Eccleston-Turner M, Rourke M, et al. Legal agreements: barriers and enablers to global equitable COVID-19 vaccine access. Lancet 2020;396:800-2.

35 Saksena N. Global justice and the COVID-19 vaccine: limitations of the public goods framework. Glob Public Health 2021;16:1512-21.

36 So AD, Woo J. Achieving path-dependent equity for global COVID-19 vaccine allocation. Med 2021;2:373-7.

37 Soares AA. Ensuring equitable access to COVID-19 vaccines. Bull World Health Organ 2020;98:826-7.

38 The Lancet. Global governance for COVID-19 vaccines. Lancet 2020;395:1883.

39 Towse A, Chalkidou K, Firth I, et al. How should the world pay for a coronavirus disease (COVID-19) vaccine? Value Health 2021;24:625-31.

40 Fidler DP. Negotiating equitable access to influenza vaccines: global health diplomacy and the controversies surrounding avian influenza H5N1 and pandemic influenza H1N1. PLoS Med 2010;7:e1000247.

41 Rourke MF, Design Aby. Access by design, benefits if convenient: a closer look at the pandemic influenza preparedness framework's standard material transfer agreements. Milbank Q 2019;97:91-112.

42 Sawal I, Ahmad S, Tariq W, et al. Unequal distribution of COVID-19 vaccine: a looming crisis. J Med Virol 2021;93:5228-30.

43 Sharma S, Kawa N, Gomber A. WHO's allocation framework for COVAX: is it fair? J Med Ethics 2021;09:1-5.

44 Usher AD. South Africa and India push for COVID-19 patents ban. Lancet 2020;396:1790-1.

45 Wouters OJ, Shadlen KC, Salcher-Konrad M, et al. Challenges in ensuring global access to COVID-19 vaccines: production, affordability, allocation, and deployment. Lancet 2021;397:1023-34.

46 Abbott FM, Reichman JH. Facilitating access to Cross-border supplies of patented pharmaceuticals: the case of the COVID-19 pandemic. J Int Econ Law 2020;23:535-61.

47 lacobucci G. Covid-19: how will a waiver on vaccine patents affect global supply? BMJ 2021;373:n1182. 
48 McMahon A. Global equitable access to vaccines, medicines and diagnostics for COVID-19: the role of patents as private governance. $J$ Med Ethics 2020;30:30.

49 Fedson DS. Preparing for pandemic vaccination: an international policy agenda for vaccine development. J Public Health Policy 2005;26:4-29.

50 Fedson DS. Pandemic influenza and the global vaccine supply. Clin Infect Dis 2003;36:1552-61.

51 Torres I, Artaza O, Profeta B, et al. COVID-19 vaccination: returning to who's health for all. Lancet Glob Health 2020;8:e1355-6.

52 Yamey G, Schäferhoff M, Hatchett R, et al. Ensuring global access to COVID-19 vaccines. Lancet 2020;395:1405-6.

53 Usher AD. CEPI criticised for lack of transparency. Lancet 2021;397:265-6.

54 Turner M. Vaccine procurement during an influenza pandemic and the role of advance purchase agreements: lessons from 2009-H1N1. Glob Public Health 2016;11:322-35.

55 So AD, Woo J. Reserving coronavirus disease 2019 vaccines for global access: cross sectional analysis. BMJ 2020;371:371.

56 Forman R, Anderson M, Jit M, et al. Ensuring access and affordability through COVID-19 vaccine research and development investments: a proposal for the options market for vaccines. Vaccine 2020;38:6075-7.

57 Usher AD. COVID-19 vaccines for all? Lancet 2020;395:1822-3.

58 The Lancet. Access to COVID-19 vaccines: looking beyond COVAX. Lancet 2021;397:941.

59 Choi EM. COVID-19 vaccines for low- and middle-income countries. Trans R Soc Trop Med Hyg 2021;115:447-56.

60 Sadeghi R, Masoudi MR, Khanjani N. The commitment for fair distribution of COVID-19 vaccine among all countries of the world. Res Nurs Health 2021:44:266-7.

61 Šehović AB, Govender K. Addressing COVID-19 vulnerabilities: how do we achieve global health security in an inequitable world. Glob Public Health 2021;16:1198-208.

62 Pagliusi S, Dennehy M, Kim H, et al. Vaccines, inspiring innovation in health. Vaccine 2018;36:7430-7.

63 Ruscio BA, Hotez P. Expanding global and national influenza vaccine systems to match the COVID-19 pandemic response. Vaccine 2020;38:7880-2.

64 World Health Assembly Resolution. WHA 61.21. global strategy and plan of action on public health, innovation and intellectual property. Geneva: 61st World Health Assembly, 2008.

65 World Health Assembly Resolution. WHA65.17 global vaccine action plan. 65th World health assembly. Geneva: WHO, 2012.

66 World Health Assembly Resolution. WHA67. 21. Access to biotherapeutic products including similar biotherapeutics products and ensuring their quality, safety and efficacy. Sixty-Seventh World Health Assembly, 2014

67 World Health Assembly Resolution. WHA67.22 access to essential medicines. Sixty-seventh World Health Assembly, 2014.

68 World Health Assembly Resolution. WHA70.3 COVID-19 response. Seventy-Third World Health Assembly, 2020.

69 World Health Organization. Endorsements of the Solidarity Call to Action 2020 [cited 2020 September 23]. Available: https://www.who. int/emergencies/diseases/novel-coronavirus-2019/global-researchon-novel-coronavirus-2019-ncov/covid-19-technology-access-pool/ endorsements-of-the-solidarity-call-to-action [Accessed 24 Sep 2020].

70 World Health Organization. COVID-19 technology access pool Launch. Geneva: World Health Organization, 2020.

71 World Heaøth Organization. A global framework to ensure equitable and fair allocation of Covid-19 products. Geneva: WHO, 2020.

72 Huneycutt B, Lurie N, Rotenberg S, et al. Finding equipoise: CEPI revises its equitable access policy. Vaccine 2020;38:2144-8.

73 Coalition for Epidemic Preparedness Innovations. CEPI policy documentation: equitable access policy, 2017. Available: https:// msfaccess.org/sites/default/files/2018-09/CEPloriginalPolicy_2017. pdf [Accessed 17 Dec 2020].

74 Coalition for Epidemic Preparedness Innovations. Equitable Access Policy - 2019 Olso Coalition for Epidemic Preparedness Innovations, 2019. Available: https://cepi.net/wp-content/uploads/2019/01/ Equitable-Access-Policy.pdf [Accessed 23 July 2020].

75 Rizvi Z. COVAX's choices. Washington, DC: Public Citizen, 2020

76 Australian Broadcasting Coporation. Millions of Pfizer booster shots locked in as government plans to continue vaccinations into 2023 [cited 202126 July], 2021. Available: https://www.abc.net.au/news/ 2021-07-25/australia-secures-millions-of-pfizer-covid19-boostershots/100321632

77 New York Times. First U.S. Vaccines Will Go to 'Wide Range' of Nations In Need: New York Times; [cited 202120 June], 2021.
Available: https://www.nytimes.com/2021/06/03/us/politics/vaccinedonations-coronavirus-biden.htm

78 US Government International Development Finance Corporation. Defense Production Act (DPA) 2021 [cited 202115 June]. Available: https://www.dfc.gov/dpa [Accessed 15 June 2021].

79 Mascarenhas A, Raghavan P. Shortage of vaccine raw materials, SII CEO to Biden: End export embargo: The Indian Express; [cited 202115 June], 2021. Available: https://indianexpress.com/article/ india/covid-vaccine-export-raw-material-sii-adar-poonawalla-seruminstitute-7277089 [Accessed 15 June 2021].

80 Arora N, Das K, Jain R. EXCLUSIVE: India unlikely to resume sizable COVID-19 vaccine exports until October: Reuters; [cited 2021 15 June], 2021. Available: https://www.reuters.com/world/india/ exclusive-india-unlikely-resume-sizable-covid-19-vaccine-exportsuntil-october-2021-05-18/ [Accessed 15 June 2021].

81 Khamsi R. If a coronavirus vaccine arrives, can the world make enough? Nature 2020;580:578-80.

82 Smyth J. Australian PM apologises for slow Covid vaccine rollout as cases rise: financial times, 2021. Available: https://www.ft.com/ content/0d5be58c-ff44-4186-91e7-000658cc4e67 [Accessed 22 July 2021].

83 Kosaka M, Hashimoto T, Ozaki A, et al. Delayed COVID-19 vaccine roll-out in Japan. Lancet 2021;397:2334-5.

84 Mihigo R, Torrealba CV, Coninx K, et al. 2009 Pandemic influenza A virus subtype $\mathrm{H} 1 \mathrm{~N} 1$ vaccination in Africa--successes and challenges. $J$ Infect Dis 2012;206 Suppl 1:S22-8.

85 World Health Organization Regional Office for Africa. H1N1 pandemic influenza vaccine deployment in the African region: Debriefing meeting. World Health Organization Regional Office for Africa, 2010.

86 World Health Organization. COVID-19 vaccine country readiness and delivery: World Health Organization; [cited 202120 June], 2021. Available: https://www.who.int/initiatives/act-accelerator/covax/ covid-19-vaccine-country-readiness-and-delivery [Accessed 20 June 2021].

87 Mwai P. Covid-19 vaccines: Why some African states can't use their vaccines British Broadcastsing Corporation: British Broadcastsing Corporation; [cited 202121 June], 2021. Available: https://www.bbc. com/news/56940657 [Accessed 21 June 2021].

88 Samarasekera U. Bhutan: small nation, big ideas affecting respiratory health. Lancet Respir Med 2021:9:e67-8.

89 Deutsche Welle.com. The COVID-19 vaccines: Where do they come from? Where will they go?: Deutsche Welle; [cited 2021 27 July], 2021. Available: https://www.dw.com/en/the-covid-19vaccines-where-do-they-come-from-where-will-they-go/a-56134178 [Accessed 27 July 2021].

90 World Health Organization. Establishment of a COVID-19 mRNA vaccine technology transfer hub to scale up global manufacturing: World Health Organization; [updated 16 April 2021; cited 202127 July], 2021. Available: https://www.who.int/news-room/articlesdetail/establishment-of-a-covid-19-mrna-vaccine-technologytransfer-hub-to-scale-up-global-manufacturing [Accessed 27 July 2021].

91 World Health Organization. WHO Director-General commends United States decision to support temporary waiver on intellectual property rights for COVID-19 vaccines: World Health Organization; [updated 5 May 2021; cited 202115 June], 2021. Available: https://www.who.int/news/item/05-05-2021-who-director-generalcommends-united-states-decision-to-support-temporary-waiveron-intellectual-property-rights-for-covid-19-vaccines [Accessed 15 June 2021].

92 Coation for Epidemic Preparedness Innovations. Survey launched by CEPI to track multinational vaccine manufacturing capacity for use in future epidemics and pandemics: Coation for Epidemic Preparedness Innovations; [updated 19 May 2021; cited 2021 15 June], 2021. Available: https://cepi.net/news_cepi/surveylaunched-by-cepi-to-track-multinational-vaccine-manufacturingcapacity-for-use-in-future-epidemics-and-pandemics/ [Accessed 15 June 2021].

93 Africa Union and Africa Centers for Disease and Prevention. African Union and Africa CDC launches Partnerships for African Vaccine Manufacturing (PAVM), framework to achieve it and signs 2 MoUs: Africa Union and Africa Centers for Disease and Prevention; [updated 16 April 2021; cited 202115 June], 2021. Available: https://africacdc. org/news-item/african-union-and-africa-cdc-launches-partnershipsfor-african-vaccine-manufacturing-pavm-framework-to-achieve-itand-signs-2-mous/

94 United Nations. Low-income countries have received just 0.2 per cent of all COVID-19 shots given: United Nations; [updated 9 April 2021; cited 202121 June], 2021. Available: https://news.un.org/en/ story/2021/04/1089392 [Accessed 21 June 2021]. 